\title{
Electrochemical Evidences for the Enhancement of Heterogeneous Electron Transfer Rates of Riboflavin in the Presence of Copper
}

\author{
Md. Abdul Jabbar*1, Shaila Salahuddin², Rowshan Jahan Mannan and Abu Jafar Mahmood \\ ${ }^{1}$ Department of Chemistry, Dhaka University, Dhaka-1000, Bangladesh \\ ${ }^{2}$ The University of Information, Technology \& Sciences (UITS), Bangladesh
}

(Received: 13 March 2014; Accepted: 8 April 2014)

\begin{abstract}
Evidences for the enhancement of the heterogeneous electron transfer rates of riboflavin in the presence of copper in aqueous medium with a glassy carbon electrode were investigated by cyclic voltammetry, chronocoulometry and differential anodic stripping pulse voltammetry. It was found that copper exhibits a multi-nuclear complex with riboflavin in aqueous KCl solution. The overall stability constant of the complex was calculated $(\log \beta=11.17)$, which is in a good agreement for the formation of a stable copper-riboflavin complex.
\end{abstract}

Key words: Metal-Ligand interaction, Voltammetry, Heterogenous electron-transfer rate, Stability constant

\section{Introduction}

Riboflavin (Vitamin $\mathrm{B}_{2}$ ) is the second member of vitamin $\mathrm{B}$ complex and an essential precursor for flavin mononucleotide and flavin adenine dinucleotide coenzymes. These co-enzymes take part in tissue oxidation as components of the electron transport system $^{1}$. The two keto groups in the isoalloxazine ring present in the flavins (Scheme 1) are easily reducible and make riboflavin redox active ${ }^{1}$. Riboflavin can also be described as a biological chelating ligand due to the existence of nitrogen and oxygen atoms on its structure that can act as coordinating sites for metal ion chelation.<smiles>Cc1cc2c3c(nc4c(=O)[nH]c(=O)nc-4n3CC(O)C(O)C(O)COP(=O)(O[NH3+])O2)c1C</smiles>

Scheme 1. The structure of Riboflavin-5-sodium phosphate

Previous studies suggest that the redox process of the flavins is thermodynamically reversible and involves formation of quinone, semiquinone and hydroquinone intermediates ${ }^{2-4}$. The electrochemical characterization of riboflavin has been examined by Zhang, H.et.al ${ }^{5}$. The enhancement of the electrochemical signal of riboflavin could also be useful in studying this coenzyme composition for its effects on metabolism, nutrition and as a photosensitive agent ${ }^{6-7}$. It was suggested that riboflavin undergoes a series of proton-coupled electron transfer reactions in dimethyl sulfoxide solutions and is initially reduced by one electron to form the radical anion and the chemical reactions were completely chemically reversible $^{8-9}$. Our previous studies also suggest that riboflavin undergoes a one-electron transfer reaction in aqueous solution and exhibited reversible heterogenous electron transfer with a glassy carbon electrode ${ }^{10}$. It was also found in the same study that the heterogeneous electron transfer rate of riboflavin enhanced at a glassy carbon electrode in the presence of cadmium ${ }^{10}$. It is well known that metals with suitable ligands are chemically more significant and specific than the metal ions ${ }^{11}$. Copper is an essential trace element, which plays an important role in biological process in human body ${ }^{12}$. There are many synthetic and biochemical studies were carried out towards understanding the structures and/or reactivity of either mono or multinuclear copper-ligand binary complexes ${ }^{13-15}$. The stability constant for different metal-ligand complexes is very much important for a variety of intercellular metal ions and biological ligands ${ }^{16}$. In this paper, we shall report the influence of copper on the heterogeneous electron transfer of riboflavin with a glassy carbon electrode in aqueous solution.

\section{Experimental}

Apparatus

All the voltammetric experiments were carried out by using a BAS 100B electrochemical analyzer, procured from Bioanalytical System Inc.(BASi) USA and Advanced Analytics (USA), Model HQ-2040. The analyzer is connected to a three electrode micro-cell consisting of a glassy carbon working electrode, a $\mathrm{Ag} / \mathrm{AgCl}$ reference electrode and a Pt-wire counter electrode. The cell is completely shielded by a Faraday cage to avoid any perturbing noises. The Faraday cage is a BAS C-3 cell stand connected with a $\mathrm{N}_{2}$ gas cylinder. A continuous flow of nitrogen has been ensured before start of any electrochemical experiment. A mercury film glassy carbon electrode (MFGCE) was working electrode for the differential pulse anodic stripping voltammetric (DPASV) experiments.

\section{Preparation of mercury film}

Mercury film was prepared on a properly polished and washed glassy carbon electrode in $10 \mathrm{~mL}$ of $5.0 \times 10^{-3} \mathrm{M}$ mercury (II) solution. The solution was purged with dry nitrogen for 10 minutes to remove the dissolved oxygen. The electrodes were connected to the analyzer. Any bubbles adhering to the electrodes were removed by tapping them off. The mercury film deposition was done 
at $-400 \mathrm{mV}$ for 120 seconds by following differential pulse anodic stripping voltammetry.

\section{Chemicals}

Riboflavin-5-sodium phosphate was procured from Beximco Pharmaceutical Company, Bangladesh and used without further purification. Copper nitrate, $\mathrm{Cu}\left(\mathrm{NO}_{3}\right)_{2}$ was purchased from Merck and was used in the experiment without further purification. $0.3 \mu \gamma-\mathrm{Al}_{2} \mathrm{O}_{3}$ has been used to polish the glassy carbon electrode. All the solutions were prepared from Milli-Q water. Before each experiment, the solutions were degassed in the cell with pure $\mathrm{N}_{2}$ gas (Bangladesh Oxygen Company) and all the runs were taken under the $\mathrm{N}_{2}$ atmosphere.

\section{Results and Discussion}

Comparative current-voltage data of riboflavin, copper and copper-riboflavin systems

Preliminary investigations to find out the enhancement of the heterogeneous charge transfer of riboflavin in the presence of copper were predicted from the comparative current-voltage data obtained from cyclic voltammograms (CVs) of riboflavin, copper and riboflavin in the presence of copper. For this reason, CVs of $1.0 \times 10^{-3} \mathrm{M}$ copper in the presence and absence of riboflavin $\left(1: 1\right.$ ratio: each $\left.1.0 \times 10^{-3} \mathrm{M}\right)$ in $0.1 \mathrm{M} \mathrm{KCl}$ solution at $50 \mathrm{mV} / \mathrm{s}$ scan rate have been carried out and represented in Figure 1.

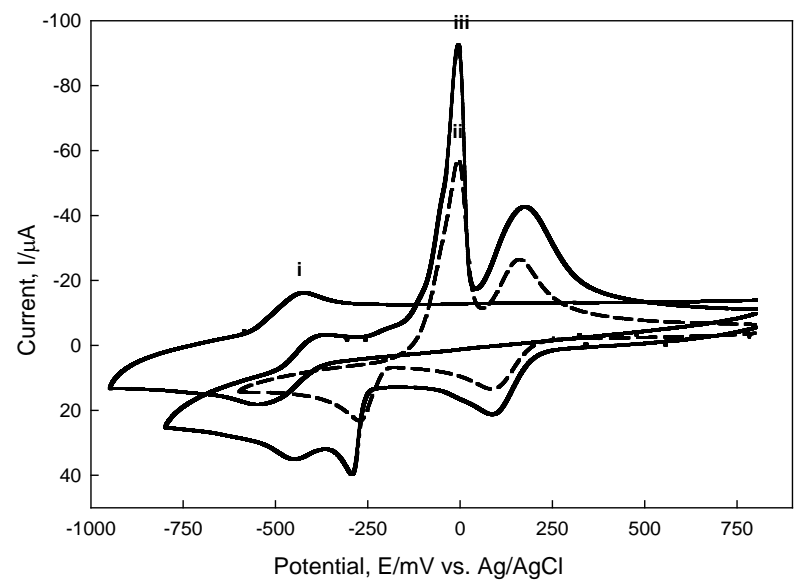

Fig. 1. Cyclic voltammograms of (i) riboflavin, (ii) copper (II) and (iii) copper-riboflavin systems at $50 \mathrm{mV} / \mathrm{s}$ scan rate. The concentration of each species is $1.0 \times 10^{-3} \mathrm{M}$

According to Figure 1, curves i, ii and iii represent the CVs of riboflavin, copper and copper in the presence of riboflavin, respectively. The cyclic voltammogram of riboflavin (curve i in Figure 1) shows an anodic and a cathodic peak at $530.08 \mathrm{mV}$ and $463.08 \mathrm{mV}$, respectively with a glassy carbon electrode. The peak separation value is $67.0 \mathrm{mV}$, which clearly indicated that the redox process is reversible involving single electron transfer. In our previous research ${ }^{10}$, it was reported that $\mathrm{CV}$ of riboflavin exhibited a single-step reversible electron- previous process. Curve ii (dotted line) in Figure 1 represents the $\mathrm{CV}$ of Copper solution in which pairs of anodic and cathodic peaks indicate the redox reaction
$\mathrm{Cu}^{2+} \stackrel{e^{-}}{\longrightarrow} \mathrm{Cu}^{+} \stackrel{e^{-}}{\longrightarrow} \mathrm{Cu}^{0}$. These processes have been occurred at $+181.8 \mathrm{mV}$ (anodic) \& +84.6 mV (cathodic) and $-24.4 \mathrm{mV}$ (anodic) \& $-236.3 \mathrm{mV}$ (cathodic), respectively with a glassy carbon electrode. However, in the presence of riboflavin, the cyclic voltammetric behaviour of copper has been changed dramatically as shown in curve iii in Figure 1. We can see that in presence of copper, riboflavin undergoes a series of electron transfer reactions. In the cathodic scan, there are three peaks appeared at $+89.46 \mathrm{mV},-297.0 \mathrm{mV}$ and $463.44 \mathrm{mV}$, respectively in the cathodic scan and the corresponding anodic peaks observed at $-401.5 \mathrm{mV},-12.0$ $\mathrm{mV}$ and $+170.02 \mathrm{mV}$, respectively. In all of the cases, the peak current for the copper-riboflavin system increases compare to riboflavin and copper. This indicates that the heterogeneous electron-transfer is faster for copperriboflavin than copper and riboflavin. Moreover, the peak potential for the copper-riboflavin system shifted to more anodic position compare to riboflavin. The shifted cathodic and anodic peaks of copper-riboflavin compared to riboflavin peaks are $66.68 \mathrm{mV}$ and $61.58 \mathrm{mV}$, respectively. Whereas, the peak potential difference $(\Delta \mathrm{Ep})$ is $61 \mathrm{mV}$ (cathodic and anodic peaks of copperriboflavin at $-463.4 \mathrm{mV}$ and $-401.5 \mathrm{mV}$, respectively) clearly suggests that the redox process in this step of copper-riboflavin system involves one-electron transfer. The first two peaks of copper-riboflavin system in its cathodic scan observed at $+89.46 \mathrm{mV}$ and $-297.0 \mathrm{mV}$ can be compared to the corresponding peaks of copper, which were observed at $+89.46 \mathrm{mV}$ and $-278.0 \mathrm{mV}$, respectively. It should be noted that there is almost no shift in the peak potential for these two steps of copperriboflavin as compared to copper and the similar trends have been observed in its anodic scan. However, the peak currents increase for both cathodic and anodic steps of copper-riboflavin compare to copper. This suggest that electron-transfer rate of copper-riboflavin should be faster than copper.

Comparative heterogeneous electron transfer rate of riboflavin, copper and copper-riboflavin systems

To study the comparative heterogeneous electron-transfer rates, the overall rate constants $\left(k_{\mathrm{f}}\right)$ of riboflavin ${ }^{10}$, copper and copper-riboflavin system have been compared. To calculate the heterogeneous electron transfer rate coefficient of copper-riboflavin, the variable concentration dependence current-voltage data has been constructed and represented in Figure 2. This data was fitted in equation $(4)^{17}$ to obtain the heterogeneous electrontransfer rate constant $\left(k_{\mathrm{f}}\right)$ for copper-riboflavin system.

$$
\begin{aligned}
& \frac{i}{n f A}=k_{f} C_{o x}-k_{r} C_{r e d} \\
& \frac{k_{f}}{k_{r}}=Q=\exp \left[\frac{R T}{n F}\left(E-E^{o^{\prime}}\right)\right] \\
& \text { where, } E^{o^{\prime}}=\frac{E_{p c}+E_{p a}}{2}
\end{aligned}
$$


For simplicity, we treated the present system as an ideal reversible redox system and for such ideal reversibility, $k_{f}$ (forward heterogeneous electron transfer rate co-efficient) should be equal to $k_{\mathrm{r}}$ (reverse heterogeneous electron transfer rate co-efficient) and equation (1) becomes,

$$
i=2 n \frac{F}{R T} A k_{o} C_{\infty}
$$

where, $f=\frac{F}{R T}, k_{\mathrm{o}}$ is the formal heterogeneous rate coefficient and $C_{\infty}$ is the bulk-concentration of the analyte ${ }^{17}$.

Thus, it is easy to calculate $k_{0}$ for individual runs at room temperature and also can be calculated from the fitted data.

The individual heterogeneous electron-transfer rate constants $\left(k_{0}\right)$ using variable concentrations of riboflavin have been calculated and the values vary within the range $0.340-0.540 \times 10^{-3} \mathrm{~cm} / \mathrm{s}$. From the fitted data $k_{0}$ was obtained $0.425 \times 10^{-3} \mathrm{~cm} / \mathrm{s}$. To calculate $k_{\mathrm{o}}$ for copperriboflavin and copper, we use Figure (1) and (2) and the calculated current-voltage data and $k_{\mathrm{o}}$ at different concentrations have been compiled in Table 1.

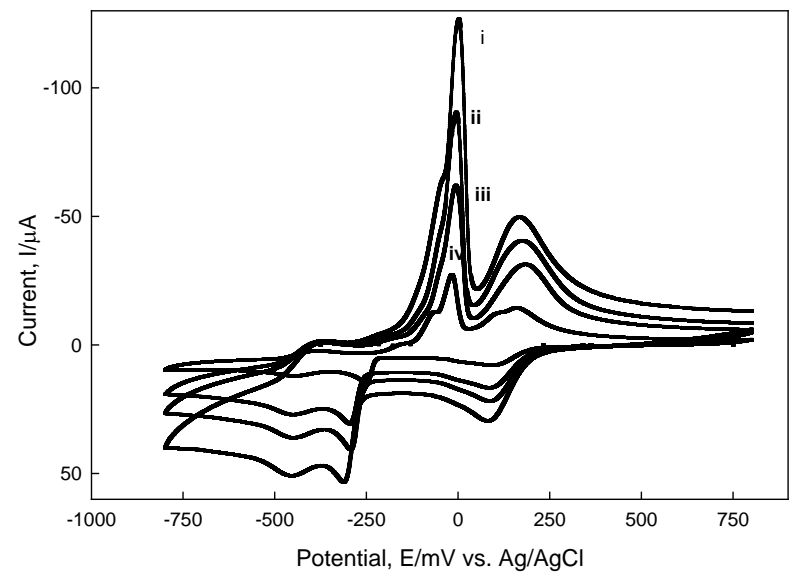

Fig. 2. Cyclic voltammograms of copper-riboflavin solution in $0.1 \mathrm{M} \mathrm{KCl}$ solution with a glassy carbon electrode at various scan rates $(\mathrm{mV} / \mathrm{s})$. (i) $1.0 \times 10^{-3}$ (ii) $2.0 \times$ $10^{-3}$ (iii) $3.0 \times 10^{-3}$ and (iv) $4.0 \times 10^{-3} \mathrm{M}$

Table 1. Current-potential and kinetic data for (A) copper-riboflavin and (B) copper in $0.10 \mathrm{M}$ KCl solution with a glassy carbon electrode at different concentrations. Scan rate: $50 \mathrm{mV} / \mathrm{s}$

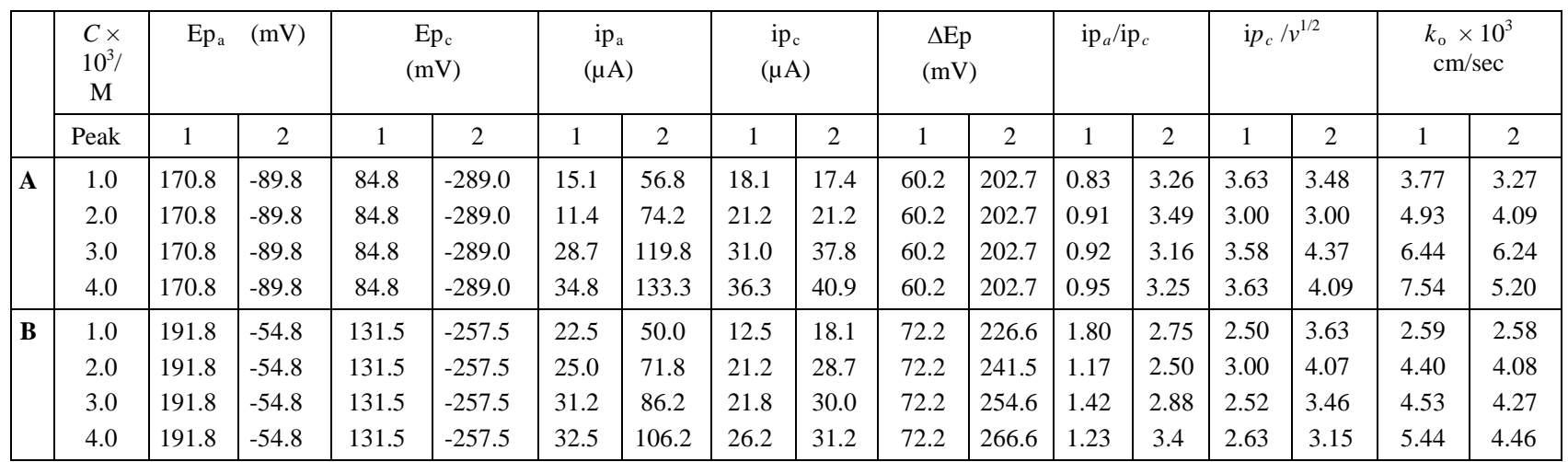

$\mathrm{Ep}_{\mathrm{a}}=$ anodic peak potential; $\mathrm{ip}_{\mathrm{a}}=$ anodic peak current; $\mathrm{Ep}_{\mathrm{c}}=$ cathodic peak potential; ip $\mathrm{p}_{\mathrm{c}}=\mathrm{cathodic}_{\text {peak }}$ current; $\mathrm{C}=\mathrm{Concentration}$ ratio of copper and riboflavin $(1: 1) ; k_{0}=$ heterogeneous electron transfer rate constant

From Table 1, it can be shown that the $k_{0}$ values of copper-riboflavin system vary within the range of 3.77$7.54 \times 10^{-3} \mathrm{~cm} / \mathrm{s}$, which are almost twenty times higher than the values calculated for riboflavin. These values are even higher than the copper system.

There are some difficulties for such calculation and to fit the data in equation (4) because, copper-riboflavin and copper both undergo a multiple-electron transfer in their redox processes and in the anodic scan small fragments of peaks were obtained (Figure 1 and 2), which make the redox reaction more complicated to understand and it cannot be properly explained from the cyclic voltammograms. Therefore, we carried out potential steps experiments (double potential step chronocoulometry) for riboflavin, copper and copper-riboflavin systems by applying same potential steps and calculate the heterogeneous electron transfer rate constant strictly under diffusion controlled condition. 

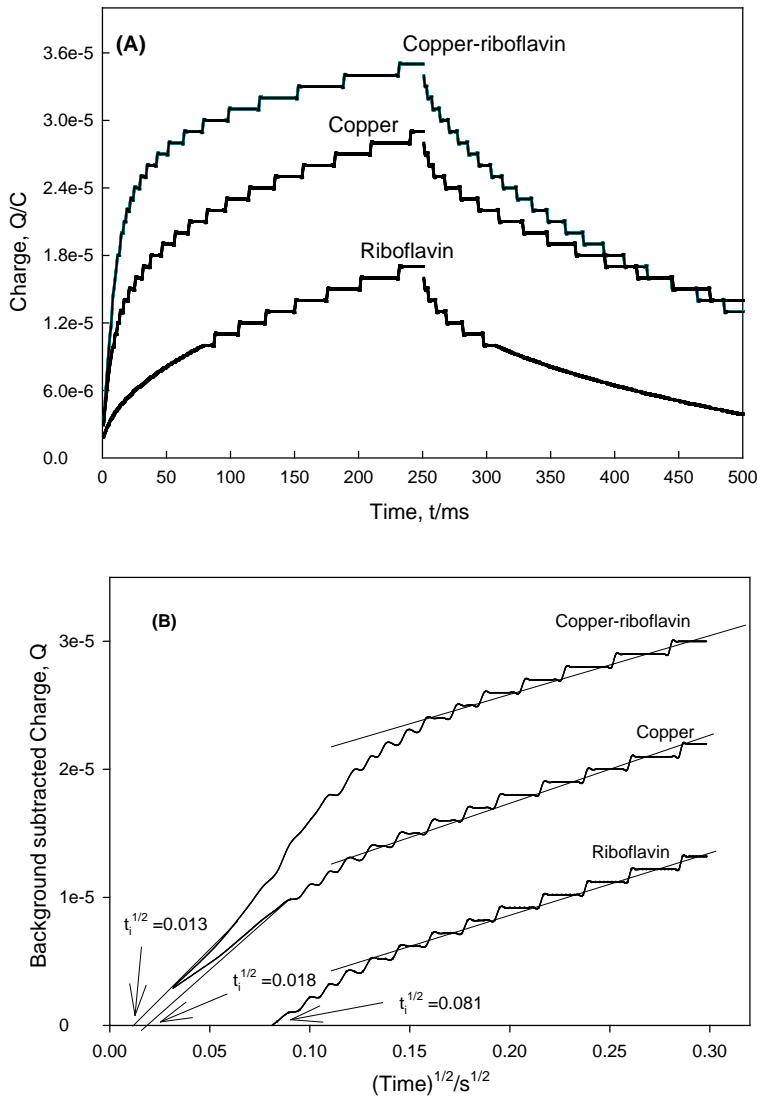

Fig. 3. (A) Relative chronocoulograms of $1.0 \times 10^{-3} \mathrm{M}$ copperriboflavin (molar ratio=1:1) copper and riboflavin solution in $0.1 \mathrm{mM} \mathrm{KCl}$ solution at a glassy carbon electrode (B) Chronocoulometric kinetic plots of the respective solutions

Figure 3 (A) represents relative chronocoulograms (CCs) of copper-riboflavin, copper and riboflavin, separately. For copper-riboflavin system, initially the potential was stepped at $+800 \mathrm{mV}$ and $250 \mathrm{~ms}$ delayed for double layer charging and then it was stepped again in the cathodic region at $-800 \mathrm{mV}$ and $250 \mathrm{~ms}$ deployed for electrolysis of the solution and the data was collected. The same condition was applied for copper and riboflavin. From these CCs, chronocoulometric kinetic plots ${ }^{18}$ of the respective solutions were constructed and represented in Figure 3 (B). From the CCs, heterogeneous electron transfer rate constants $\left(k_{\mathrm{f}}\right)$ have been calculated by using the equations (5) and (6):

$$
\begin{aligned}
& k_{\mathrm{f}}=\frac{\text { slope } \times \mathrm{H} \times \mathrm{Q}^{1 / 2}}{2 \mathrm{nFAC}_{\mathrm{O}}^{0}} \\
& \text { where, } \mathrm{H}=\frac{\mathrm{\square}^{1 / 2}}{2 \mathrm{t}_{\mathrm{i}}^{1 / 2}}
\end{aligned}
$$

$\mathrm{t}_{\mathrm{i}}{ }^{1 / 2}$ can be obtained by extrapolating the straight line obtained from the plot of background subtracted charge, Q vs. $t^{1 / 2}$. The Tafel slope in equation (5) can be obtained from the linear part of the chronocoulometric kinetic plot as indicated in Figure $3(\mathrm{~B})$. The calculated heterogeneous electron transfer rate constants, $\left(k_{\mathrm{f}}\right)$, Tafel slopes and $\mathrm{t}_{\mathrm{i}}{ }^{1 / 2}$ values for copper-riboflavin, copper and riboflavin are tabulated in Table 2. From this data, it is confirmed that the heterogeneous electron transfer rate of the riboflavin is enhanced in the presence of copper.

Table 2. Comparative calculated parameters for Copperriboflavin, copper and riboflavin from chronocoulometric data

\begin{tabular}{l|c|c|c}
\hline System & $\begin{array}{c}\text { Tafel slope } \\
\times 10^{-4}\end{array}$ & $\begin{array}{c}\mathrm{t}_{\mathrm{i}}{ }^{1 / 2} \\
/ \mathrm{ms}\end{array}$ & $\begin{array}{c}\text { Heterogeneous electron } \\
\text { transfer rate constant }\left(k_{\mathrm{f}}\right) \times \\
10^{2} \mathrm{~cm} / \mathrm{s}\end{array}$ \\
\hline $\begin{array}{l}\text { Copper- } \\
\text { riboflavin }\end{array}$ & 2.108 & 0.013 & 5.279 \\
$\begin{array}{l}\text { Copper(II) } \\
\text { Riboflavin }\end{array}$ & 1.957 & 0.018 & 3.531 \\
\hline
\end{tabular}

Stability constant for copper-riboflavin complex by differential pulse anodic stripping voltammetric (DPASV) method

To investigate the reason for the enhancement of heterogeneous electron transfer rate of riboflavin in the presence of copper, DPASV experiments for copper and copper-riboflavin solutions were performed with a mercury film glassy carbon electrode (MFGCE) in aqueous $\mathrm{KCl}$ solution with trace amount of $0.1 \mathrm{M} \mathrm{HCl}$ solution. From this experiment it was revealed that an stable 1:1 copper-riboflavin complex is formed between copper and riboflavin. For the DPASV experiment, at first a solution of copper with $\mathrm{pH} 5.9$ was recorded between switching potential 0 and $800 \mathrm{mV}$ respectively. $D P A S V$ of copper shows two sharp peaks at $-462.69 \mathrm{mV}$ and $-158.21 \mathrm{mV}$, respectively according to Figure 4.

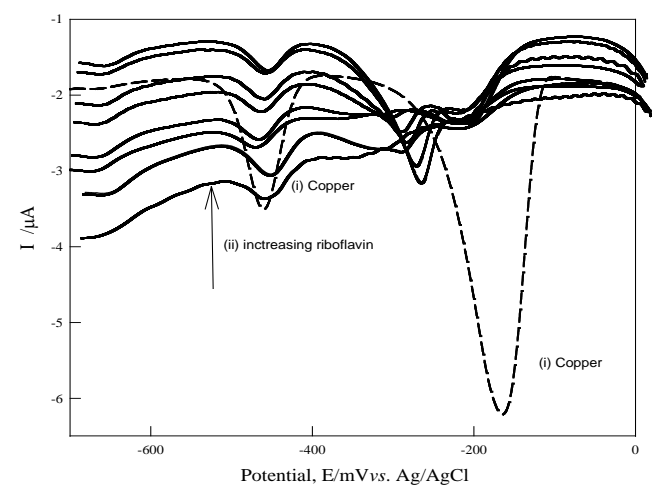

Fig. 4. DPASV for copper and copper-riboflavin in $0.10 \mathrm{M} \mathrm{KCl}$ solutions at a mercury film glassy carbon lectrode MFGCE with the addition different oncentration of riboflavin. (i) [copper] $=1.0 \times 10^{-9} \mathrm{M}$; (ii) $[$ riboflavin] $=$ $(0.1,0.2,0.6,1.0,5.0,10.0,20.0 \& 30.0) \times 10^{-9} \mathrm{M}$

By keeping the concentration of copper constant at $1.0 \times$ $10^{-9} \mathrm{M}$, the concentration of riboflavin was increased gradually. This results a shift in the cathodic peak of copper to more cathodic direction and the peak potentials shifted from $-462.69 \mathrm{mV}$ to $-474.63 \mathrm{mV}$ and from $158.21 \mathrm{mV}$ to $-301.49 \mathrm{mV}$ respectively. Further a new peak appears at $-355.00 \mathrm{mV}$. Shifting of peak potential of copper toward the cathodic position and decrease in the peak current value in DPASV experiment clearly indicates for the formation of complex between copper and riboflavin (Figure 4). 
The DPASV experiments allow us to calculate the overall stability constant of the copper-riboflavin complex and calculated according to de Ford and Hume method ${ }^{19}$. According to this method, the formation constant of the Copper-riboflavin complex can be obtained from the following equation.

$F_{0}\left[\right.$ riboflavin] $=\operatorname{antilog}\left\{0.434 n F / R T\left(E p_{(s)}-E p_{(c)}\right)+\right.$ $\left.\log I_{s} / I_{c}\right\}$

Where, $E p_{(\mathrm{s})}$ and $E p_{(\mathrm{c})}$ are the peak potentials for the copper and copper-riboflavin complex, respectively and $I_{s}$ and $I_{c}$ are their corresponding diffusion currents. $F_{0}$ [riboflavin] can be obtained from the following equation.

$F_{0}[$ riboflavin $]=\beta_{0}+\beta_{1}[$ riboflavin $]$

$\gamma_{\text {Copper }} \gamma_{\text {riboflavin }}$

$\gamma_{\text {Copper-riboflavin }}$

The polynomial form of this equation can be given by the following equation,

$$
\begin{aligned}
& F_{0}[\text { riboflavin }]=\beta_{0}+\beta_{1}[\text { riboflavin }]+ \\
& \beta_{2}[\text { riboflavin }]^{2}+\ldots \ldots \ldots \ldots . .
\end{aligned}
$$

where, $\beta_{1}, \beta_{2} \ldots \ldots \ldots \ldots$ are the stability constants of the complexes with one, two, etc. molecules of riboflavin, respectively.

The formation constant $F_{1}$ [riboflavin] is defined by the following equation.

$$
F_{1}[\text { riboflavin }]=\frac{F_{0}[\text { riboflavin }]-1}{[\text { riboflavin }]}, \quad \text { and the }
$$

polynomial equation can be rearranged as,

$$
\begin{aligned}
& F_{1}[\text { riboflavin }]=\left\{\frac{F_{0}[\text { riboflavin }]-1}{[\text { riboflavin }]}\right\} \\
& =\beta_{1}+\beta_{2}[\text { riboflavin }]+\beta_{3}[\text { riboflavin }]^{2}+\ldots \ldots \ldots \ldots \\
& \quad=\operatorname{antilog}\left\{0.434 n F / R T\left(E p_{(s)}-E p_{(c)}\right)+\log I_{s} / I_{c}\right\}
\end{aligned}
$$

From the experimental data, the value of $\mathrm{F}_{0}$ [riboflavin] and $\mathrm{F}_{1}$ [riboflavin] were calculated for different concentration of riboflavin and tabulated in Table 3 . It was found from Table 3 that a plot of $\mathrm{F}_{0}$ [riboflavin] $v$ s. [riboflavin] will not provide linearity. Furthermore, a polynomial fit of this plot provide us the $\log \beta$ value as 11.17. This polynomial plot suggests that a multi-nuclear complex is formed between copper and riboflavin. Furthermore, according to Table 3, the value $\mathrm{F}_{1}$ [Riboflavin] is not constant. This is also a strong evidence for the formation of multi-nuclear complex between copper and riboflavin. Similar trends of F-values by de Ford and Hume method were found in the literature $^{20-21}$ for multi-nuclear complexes. The stepwise stability constants, $\mathrm{F}_{0}$ [riboflavin] and $\mathrm{F}_{1}$ [riboflavin] and the overall stability constant, $(\log \beta=11.17)$ are all in good agreement for the formation of a stable multi-nuclear complex between copper and riboflavin and copper may be co-ordinated to the highest spin density region between nitrogen $(12)^{10}$ and oxygen $(24)^{10}$ positions of riboflavin.

Table 3. F-functions values for copper-riboflavin complex at $1.2 \times 10^{-10} \mathrm{M}$ copper in $0.1 \mathrm{M} \mathrm{KCl}$ solutions at a MFGCE

\begin{tabular}{llllll}
\hline $\begin{array}{l}\text { [Riboflavin] } \\
\times 10^{-9} \mathrm{M}\end{array}$ & $\begin{array}{l}i p_{a} \\
\mu \mathrm{A}\end{array}$ & $\begin{array}{l}-E p_{a} \\
\mathrm{mV}\end{array}$ & $\begin{array}{l}\mathrm{F}_{0} \text { [riboflavin } \\
\text { ] }\end{array}$ & $\begin{array}{l}\mathrm{F}_{1} \text { [riboflavin } \\
\text { ] } \\
\times 10^{-12}\end{array}$ & $\log \beta$ \\
\hline 0.00 & 1.68 & 462.60 & - & - & \\
0.10 & 0.36 & 474.40 & 11.88 & 1.088 & \\
0.20 & 0.44 & 486.50 & 23.49 & 1.125 & 11.2 \\
1.00 & 0.48 & 489.50 & 42.17 & 0.082 & \\
5.00 & 0.52 & 491.50 & 39.17 & 0.038 & \\
\hline
\end{tabular}

\section{Acknowledgement}

This work was financially supported by the Ministry of Science and Technology, Government of the Peoples Republic of Bangladesh.

\section{References}

1. Penzer G. R. and G. K. Radda, 1967, The Chemistry and Biological function of Isoalloxazine (Flavines), Quart. Rev., 21, 43-65.

2. P. Hemmerich, C. Veeger, H.C.S Wood, 1965, Progress in the Chemistry and Molecular Biology of Flavins and Flavocoenzymes, Angew. Chem. Int. Edit., 4,671-678.

3. Malinuskas A., T. Ruzgas and L. Gorton, 1999. Tuning the redox potential of riboflavin by zirconium phosphate in carbon paste electrodes, Bioelectrochem., Bioenerg., 49(1), 21-27.

4. Malinauskas A., 2008. Electrochemical study of riboflavin adsorbed on a graphite electrode, Chemija, 19, 1-3.

5. Zhang H., J. Zhao, H. Liu, H. Wang, R. Liu and J. Liu, 2010. Application of poly (3-methylthiophene) modified glassy carbon electrode as riboflavin sensor, Int. J. Electrochem. Sci., 5, 295-301.

6. Hagen J.A., S.N. Kim, B. Bayraktaroglu, K. Leedy, J. L. Chavez, N. Kelley-Loughnane, R. R. Naik, M. O. Stone, 2011. Biofunctionalized zinc oxide field effect transistors for selective sensing of riboflavin with current modulation, Sensors, 11, 6645-6655.

7. Yousef U.S. and M. Abdel-Azzem, 1998. A cyclic voltammetric and coulometric study of a modified electrode prepared by electrooxidative polymerization of nickel complex of 1,5-diaminonapthalene in acetonitrile, Pol. $J$. Chem.,72, 2583-2596.

8. Serena L., J. Tan and R. D. Webster, 2012. Electrochemically Induced Chemically Reversible Proton-Coupled Electron Transfer Reactions of Riboflavin (Vitamin B2). Journal of the American Chemical Society, 134 (13), 5954-5964.

9. Serena L., J. Tan, J. M. Kan and R. D. Webster, 2013 Differences in Proton-Coupled Electron-Transfer Reactions of Flavin Mononucleotide (FMN) and Flavin Adenine Dinucleotide (FAD) between Buffered and Unbuffered Aqueous Solutions. The Journal of Physical Chemistry B, 117 (44), 13755-13766.

10. Jabbar, M. A., S. Salahuddin, A. J. Mahmood, and R. J. Mannan, 2012. Voltammetric evidences for the interaction of riboflavin with cadmium in aqueous media. Journal of Saudi Chemical Society, http://dx.doi.org/10.1016/j.jscs. 2012.06.005, (in press). 
11. Kaim, W. and B. Schwederski, 1996. Bioinorganic Chemistry: Inorganic Elements of Life, John. Wiley and Sons: London., 39-262.

12. Al-Amiery A. A. H., A. Saif, M. Rawa, and A. Maysaa, 2010. "Synthesis, characterization and antibacterial study of metal complexes derived from bis(5-benzyl-1, 3, 4thiadiazol-2-yl)methane, J. Chem. and Pharm. Res., 2,(3), 120-126.

13. Michel H., J. Behr, A. Herrenga, and A. Kannt. 1998. Cytochrome C Oxidase: Structure and Spectroscopy, Annual Review of Biophysics and Biomolecular Structure; Stroud, R., Ed.; Annual Reviews Inc.: Palo Alto, CA, 27, 329-356.

14. Ferguson-Miller S. and G. T. Babcock, 1996. Heme/Copper Terminal Oxidases, Chem. Rev. 96, 2889-2907.

15. Ogura, T., T. Kitgawa, 2004. Resonance Raman Characterization of the $\mathrm{P}$ intermediate in the reaction of bovine cytochrome $C$ oxidase, Biochim. Biophys. ActaBioenergetics, 1655, 290-297.
16. J.A. Cowan, 1997. Inorganic Biochemistry, An Introduction, Second edition, Wiley-VCH, Inc., 97.

17. Gosser Jr., D. K, 1994. Cyclic Voltammetry, Simulation and Analysis of Reaction Mechanisms, Wiley-VCH, 45.

18. Christie, J. H., R. A. Osteryoung and F. C. Anson, 1967. Application of double potential-step chronocoulometry to the study of reactant adsorption, J. Electroanal. Chem. 13 (3), 236.

19. Ford, D.D.D., and D. N. Hume, 1951. The Determination of Consecutive Formation Constants of Complex Ions from Polarographic Data. J. Am. Chem. Soc., 5321,71.

20. Chanchal, K., S. Sharma and O.D. Gupta, 2010. Electrochemical Studies of Cadmium(II) Complexes with Itaconic Acid in Non-Aqueous Media at Dropping Mercury Electrode, Asian Journal of Chemistry. 22 (1), 31.

21. Chanchal, K. and O.D. Gupta, 2009. Electrochemical Studies of Cd (II) Complexes with Itaconic Acid in NonAqueous Media (20\%,40\%, 60\% DMF) AT DME, Int. J. Chem. Sci. 7(3), 1531. 